\title{
A CONSTRUÇÃO DE CONCEITOS TEÓRICOS POR MEIO DA PRÁTICA PEDAGÓGICA - FORMAÇÃO DE PROFESSORES DE LÍNGUAS
}

\author{
Elisa Novaski Cordeiro* \\ Francisco Carlos Fogaça
}

RESUMO: Este trabalho tem como objetivo analisar, sob a perspectiva dos alunos-professores em formação inicial, de que modo o trabalho prático desenvolvido por meio de monitoria voluntária durante as aulas de Português para Falantes de Outras Línguas (PFOL) colaborou com sua formação docente no curso de Letras Inglês da Universidade Tecnológica Federal do Paraná (UTFPR). Para tanto, serão explicitados os conceitos de professor reflexivo (SCHÖN, 1992; 2000) e articulação de teoria e prática nos cursos de Letras (GIMENEZ, 2005; 2011; GIMENEZ e CRISTOVÃO, 2004). O trabalho tem uma abordagem qualitativa e os dados foram coletados por meio de entrevistas semiestruturadas e transcritas integralmente. Foram entrevistados dois alunos de Letras, do $2^{\circ}$ período do Curso. Ambos participaram como monitores voluntários no programa de extensão universitária PFOL da UTFPR, campus Curitiba, que tem por intuito o atendimento a estrangeiros (aulas de português), a formação de professores em pré-serviço e o desenvolvimento de pesquisas na área de ensino de PLA. Os resultados indicam que a prática propiciada pela participação dos discentes no projeto de extensão representou, para eles, um avanço significativo em sua formação e que lhes auxiliou a relacionar conceitos teóricos abordados ao longo do curso com a prática pedagógica presente nas aulas de PFOL.

PALAVRAS-CHAVES: Ensino de PL2; Formação inicial de professores; Teoria e prática; Professor reflexivo.

\footnotetext{
* Mestre em Letras pela Universidade Federal do Paraná (UFPR). Professor Titular da Universidade Tecnológica Federal do Paraná (UTFPR).

** Doutor em Estudos da Linguagem pela Universidade Estadual de Londrina (Uel). Professor Adjunto 3 da Universidade Federal do Paraná (UFPR).
} 


\section{Introdução}

A formação de professores de segunda língua (L2) vem sendo tema de debate desde os anos 1990, aproximadamente (GIMENEZ, 2011). O aumento da visibilidade da área a partir desse período coincide com dois acontecimentos: 1) o surgimento do conceito de professor reflexivo e 2) um período chamado de virada social, no qual, segundo Figueiredo (2018) e Johnson $(2001,2009,2016)$, passa-se a entender a concepção de língua, bem como os processos de ensino/aprendizagem como fenômenos sociais e não cognitivos simplesmente.

Gimenez (2011) relata que, na década de 1970, tiveram início os cursos de pósgraduação na área de linguística aplicada. O foco dos estudos era o aluno e a língua como objeto de aprendizagem. Aspectos contextuais ou que versassem sobre as características individuais dos sujeitos não eram levados em conta. Já nos anos 1980, os estudos sobre habilidades de uso da língua, e as pesquisas sobre leitura ganharam maior destaque, bem como processos cognitivos associados à leitura. Em 1990, os sujeitos envolvidos na interação em sala ganham maior relevância nas pesquisas. O professor recebe um foco muito maior, tanto em suas ações como em sua formação. Nesse cenário, as abordagens etnográficas ganham espaço e há uma forte tendência de dar voz a todos os envolvidos no processo de ensino/aprendizagem dentro de sala de aula.

A partir de então, o foco dos estudos de ensino/aprendizagem de L2, na área de linguística aplicada, passou a ser direcionado muito mais ao professor e à sua formação. Tal fato advém do entendimento de que as práticas de sala de aula do docente se relacionam com os processos formativos pelos quais ele passou (GIMENEZ, 2011). Nesse sentido, o estudo sobre a formação de professores ganha grande relevância na área de ensino de L2.

Até então, os cursos de licenciatura em Letras se baseavam em um currículo conhecido como $3+1$ (3 anos de estudos teóricos, seguidos de 1 ano de prática didática propiciada pelos estágios supervisionados e disciplinas de prática de ensino). Esse modelo, infelizmente, ainda não se encontra extinto, mas nas últimas décadas, muito se tem discutido 
sobre a necessidade de promover uma formação docente na qual teoria e prática se retroalimentem e que sejam compreendidas realmente como princípios indissociáveis em todas as etapas do curso, não somente no ano final da licenciatura (GIMENEZ e CRISTÓVÃO, 2004; GIMENEZ, 2005; 2011; MARTINEZ, 2007; HALU, 2010).

Assim sendo, o presente trabalho tem como objetivo analisar, sob a perspectiva dos alunos-professores em formação inicial, de que modo o trabalho prático desenvolvido por meio de monitoria voluntária durante as aulas de Português para Falantes de Outras Línguas (PFOL) colaborou no entendimento de conceitos teórico-práticos durante sua formação docente no curso de Letras Inglês de uma universidade pública do sul do Brasil.

\section{Conceitos teóricos}

A base teórica deste trabalho prevê uma compreensão da formação docente baseada em experiências práticas. Para tanto, abordaremos o conceito de professor reflexivo, fazendo um recorte em relação à importância da prática pedagógica desde o início da formação, articulada com momentos de reflexão teórica.

Entre as décadas de 1990 e 2000, os estudos de Donald Schön sobre a necessidade de criar momentos de prática e reflexão durante toda a formação profissional (não só de professores, mas em diferentes áreas) começam a se intensificar. A partir desse paradigma, houve um questionamento em relação aos modelos de formação profissional vigentes até então: estudo exclusivo da teoria seguido de, nos períodos finais do curso, prática por meio de estágios supervisionados (WALLACE, 1991). O modelo desenvolvido por Schön foi amplamente estabelecido como formação profissional reflexiva.

Sobre a formação docente especificamente, Donald Schön chama a atenção para a necessidade de desenvolver no aluno-professor sua capacidade de reflexão, que seria a constante problematização em relação às atitudes e posições tomadas em sala de aula. Nessa visão, a prática (conhecimento prévio) e o conhecimento teórico devem ser articulados em momentos de prática e posterior reflexão (WALLACE, 1991). Em comparação à 
tradição vigente da época, na qual havia uma grande valorização da teoria, vista como direcionadora da prática, o modelo reflexivo coloca em evidência a necessidade de uma formação na qual se articulem prática e teoria em um nível de igual importância e visibilidade ao longo de todo o curso de formação inicial docente.

De acordo com Schön (1992), somente conhecimentos teóricos não são capazes de formar um professor que possa efetivamente cumprir sua função, já que a teoria por si só não dá conta de preparar o futuro professor para as imprevisibilidades da prática pedagógica. Segundo o pesquisador, é através da prática e da reflexão sobre as situações ocorridas na sala de aula que o docente pode elaborar estratégias para atingir seu objetivo de ensino. Todo esse processo deve prever um atendimento individualizado a cada estudante, respeitando-se suas limitações e suas características pessoais no processo de aprendizagem.

Schön (2000) exemplifica a relevância da prática no processo formativo através da relação entre designers aprendizes e seus professores. Segundo o pesquisador, a prática a qual os formandos eram submetidos era o que levava à construção de conhecimento por meio dos questionamentos e entendimento de dúvidas, isso porque há uma diferença muito grande quando somos expostos à descrição do que fazer e quando precisamos realmente realizar determinada ação. Assim, o autor pontua que, enquanto a descrição por si só não causa grandes impactos no aprendizado, na ação, somos obrigados a experimentar e a refletir sobre como e sobre o que fazemos. A descrição sem ação não faz sentido para o aluno, pois é durante o fazer que entendemos o que é descrito. Desse modo, os alunosprofessores aprendem fazendo e compartilhando suas práticas, Paulo Freire (1970/1987, p. 69) afirmava que "ninguém educa ninguém, como ninguém tampouco educa a si mesmo: os homens se educam em comunhão, mediatizados pelo mundo”. É na relação dialógica entre educadores e educandos (formadores e alunos em formação) que se estabelece o processo reflexivo, “em lugar de serem recipientes dóceis, são agora investigadores críticos, em diálogo com o educador, investigador crítico também” (FREIRE, 1970/1987, p. 69).

A definição do conceito de formação que utilizamos é baseada nas ideias levantadas por Gimenez (2005): 
(...) a formação é um processo de aprendizagem que leva em conta o aprendiz-professor e seus conhecimentos. Assim, a formação está sendo considerada naqueles contextos onde são oferecidas oportunidades para desenvolvimento com a presença de mediador mais experiente (seja na fase inicial seja na fase continuada) e ferramentas que possibilitem a articulação dos conhecimentos adquiridos ao longo de experiências anteriores e atuais. (...) A formação de professores tem sido um processo orientado para tomada de decisões. Esta consideração traz como consequência que a educação profissional tem um caráter de intervenção, cujos propósitos precisam ser explicitados e negociados durante todo o processo com os envolvidos. (GRIFO NOSSO). (GIMENEZ, 2005, p. 184).

Na visão de Gimenez (2005), a formação de professores passa por diversas esferas que consideram os indivíduos envolvidos no processo (docente e discente) assim como seus desejos, limitações e todo o contexto sócio cultural que os rodeia. A formação é considerada como um processo interventivo, ou seja, possivelmente, nem aluno, nem professor sairão dele do mesmo modo em que entraram, sendo que haverá uma troca constante de informações e vivências que resultará no desenvolvimento de ambos. Essa troca precisa ser negociada e renegociada sempre que necessário. Gimenez (2005) fala da importância da adoção de uma postura na qual sempre estejamos abertos ao diálogo e não a decisões unilaterais e verticais.

As observações levantadas por Gimenez (2005) podem sinalizar a construção de uma imagem utópica ou demasiadamente idealizada, no entanto, sempre é necessário considerar o nível de maturidade dos envolvidos no processo. Se o professor formador tem condições institucionais e se é possível, para ele, ouvir realmente seus alunos, sempre levando em conta sua maturidade, sua idade, sua capacidade de entender determinados pontos, conferindo-lhes oportunidades de experienciar determinados conceitos teóricos através da prática (ou mesmo de produzir teoria a partir da prática), todo o processo de formação pode ser muito mais significativo para todos os envolvidos. A compreensão da teoria por meio da prática pedagógica é muito mais significativa para o professor em formação. 
Nessa mesma direção, Zamboni (2013) define a formação de professores não mais como um treinamento, mas como educação de professores. Halu (2010), em consonância com essa definição, caracteriza a formação como apoiada em um modelo investigativo da experiência prática. Segundo ela, nesse modelo,

(...) futuros professores ou professores iniciantes são acompanhados por professores mais experientes ou compõem grupos de reflexão, observando suas próprias práticas, escolhendo focos para análise, levantando hipóteses, testando propostas de ação para a sala de aula e avaliando conjuntamente os resultados. (HALU, 2010, p. 103).

É importante oportunizarmos uma prática reflexiva com o fim de possibilitar ao professor em formação o desenvolvimento da capacidade de enfrentar diversas situações diárias, sendo capaz de levantar questões e de trata-las por conta própria ou refletindo com seu grupo de colegas professores. O professor formador seleciona e apresenta um campo de exploração inicial, criando condições e recursos básicos para que seus diferentes alunos possam explorar inúmeras situações a partir de seus próprios pontos de partida (Halu, 2010).

Desse modo, a aprendizagem dependerá de um processo de construção de relacionamento entre o formando e o formador. Ambos vão ocupando seus lugares e preenchendo suas expectativas em relação ao papel de cada um deles. Nesse sentido, a relação vai sendo construída ao longo do processo sem que haja repostas prontas para cada caso. Assim, Halu (2010) observa a importância de o docente formador minimizar os efeitos causados pela sensação natural do professor em formação de sentir-se perdido e vulnerável, fazendo com que tal situação se torne suportável e não prejudique a construção do conhecimento dos aprendizes.

\section{Contextualização da pesquisa}

O presente trabalho foi realizado a partir das atividades desenvolvidas por um programa de extensão desenvolvido na Universidade Tecnológica Federal do Paraná (UTFPR), 
campus Curitiba, chamado PFOL (Português para Falantes de Outras Línguas). Tal programa iniciou como um projeto em 2001 e tinha por primeiro objetivo ensinar português a estudantes intercambistas do antigo CEFET-PR (BALDIN e CORDEIRO, 2017). Em 2008, há uma reconfiguração do trabalho desenvolvido em virtude de mudanças institucionais e sociais. Entre elas: o início do Curso de Licenciatura em Português Inglês da UTFPR; a entrada de professores no Departamento Acadêmico de Línguas Estrangeiras Modernas (DALEM) com interesse na área de ensino de PFOL e o aumento da demanda de estrangeiros precisando de aulas de português.

Atualmente, contamos com cinco turmas regulares de PFOL (dos níveis 1 ao 5) ${ }^{1}$, com oferta semestral de acordo com a demanda. Os alunos estrangeiros são compostos, na sua grande maioria, por pessoas da comunidade externa e as atividades organizadas pelo grupo de pesquisa GPPFOL não se limitam às aulas regulares de 60 horas semestrais. Há uma preocupação em propiciar a esse público encontros de socialização e de interação em língua portuguesa, tais como festas tradicionais brasileiras, oficinas de diferentes temas culturais, cursos esporádicos, encontros de cinema e de debates.

Para que todos os trabalhos possam ocorrer, temos um grupo de discente dos cursos de Licenciatura em Letras Português Inglês e Letras Inglês da UTFPR (entre extensionistas voluntários e bolsistas com bolsa remunerada) que nos auxiliam como monitores de sala de aula e, também, ministrando oficinas e mini cursos sobre variados temas (sempre sob a presença e supervisão das professoras concursadas da instituição).

Nesse sentido, o programa de extensão PFOL atinge diretamente dois públicos específicos: 1) os estrangeiros (alunos ou não alunos da UTFPR) que participam das aulas de português e dos eventos gratuitamente e 2) os professores em formação inicial - alunos dos cursos de Licenciatura em Letras Português Inglês e Letras Inglês - que têm a oportunidade de vivenciar o cotidiano da sala de aula, em contato direto com alunos reais em

\footnotetext{
${ }^{1}$ As turmas são divididas de acordo com o nível de proficiência dos alunos, sendo o nível 1 o nível mais básico, e o nível 5 o mais avançado. No início de cada semestre, os alunos novos passam por uma pequena prova e por uma entrevista oral para definir o nível que frequentarão.
} 
situações reais, integrando, desse modo, prática e teoria sempre sob orientação de uma das professoras orientadoras de PFOL.

Os resultados acadêmicos desse trabalho podem ser observados a partir dos estudos já desenvolvidos das experiências vivenciadas pelos universitários no PFOL, tais como: 5 monografias de especialização; vários TCCs concluídos e em andamento; publicação de artigos e resumos em eventos acadêmicos e revistas científicas; comunicações em eventos acadêmicos; a criação de materiais digitais online através de editais REA (Recursos Educacionais Abertos) e Ações Afirmativas; organização de eventos acadêmicos sob o título de EPFOL (3 edições até o momento: 2014, 2015 e 2017).

Em relação ao trabalho desenvolvido nas aulas de língua portuguesa, os professores efetivos participantes do PFOL ministram as aulas de português. Os alunos de Letras Português Inglês ou Letras Inglês podem participar das aulas como monitores voluntários. Essa participação passa por um período de observação e de auxílio em algumas atividades desenvolvidas em sala (atividades de interação entre os alunos estrangeiros) e, aos poucos, os monitores passam a desenvolver materiais didáticos aplicados em sala e também a ministrar aulas de português (sempre na presença e sob orientação do professor titular). Em estudo publicado sobre o trabalho do PFOL desenvolvido em sala de aula pelos alunos monitores - estudantes dos cursos de Letras da UTFPR - Baldin e Cordeiro (2017) pontuam:

O objetivo da indissociação - prática e teoria - é proporcionar aos universitários a experimentação do cotidiano do professor que, além de planejar, preparar, ministrar e avaliar sua prática, preocupa-se em buscar sua formação continuada através de pesquisa e de tecnologias capazes de auxiliá-lo a entender e a superar os desafios inerentes ao trabalho de ensinar e aprender. (BALDIN e CORDEIRO, 2017, p. 98-99).

O PFOL na UTFPR também tem participação em três disciplinas regulares na grade curricular do Curso de Licenciatura em Letras Inglês, são elas: Grupo de Pesquisa PFOL (que pode ser cursado entre os períodos 2 a 6); Ensino de PFOL 1 (previsto para o $6^{\circ}$ 
período) e Ensino de PFOL 2 (previsto para $7^{\circ}$ período). A disciplina de Grupo de Pesquisa PFOL faz parte de um grupo de disciplinas do curso, cujo objetivo é apresentar aos alunos diferentes possibilidades de áreas de estudo, as quais estão disponíveis na universidade. Cada aluno deve passar por cinco disciplinas de Grupo de Pesquisa, assim, no $7^{\circ}$ período, ele já inicia a construção de seu projeto de TCC, podendo escolher entre uma das áreas de pesquisa estudadas por ele. Ao cursar uma disciplina do Grupo de Pesquisa, ao final do semestre, o aluno deve apresentar um piloto de pesquisa desenvolvido ao longo do período letivo.

A presente pesquisa foi realizada em 2017 e teve como participantes dois alunos do Curso de Licenciatura em Letras Inglês que, na época, estavam no $2^{\circ}$ período do Curso. No semestre em que o estudo foi realizado, ambos os alunos, além de participarem como monitores voluntários durante as aulas de PFOL (no programa de extensão), também cursavam concomitantemente a disciplina Grupo de Pesquisa PFOL. Devido a tal combinação, eles puderam realizar seu piloto de pesquisa a partir de sua experiência nas aulas de português.

Na disciplina Grupo de Pesquisa do PFOL, os alunos estudavam aspectos teóricos relativos ao ensino/aprendizagem de português. Concomitantemente, em sua participação como monitores voluntários nas aulas de PFOL, eles iniciaram fazendo observações, e depois passaram a auxiliar os alunos de PFOL em algumas atividades em sala. Em seguida, os acadêmicos passaram a pensar na preparação de material didático, selecionando diferentes materiais e pensando em modos de transformá-los em atividades para serem aplicadas em sala. Por fim, eles puderam preparar três aulas de $1 \mathrm{~h}$ 40min cada, ministra-las e refletir sobre a experiência. A partir dos resultados, eles desenvolveram seu piloto de pesquisa, que foi apresentado na Disciplina Grupo de Pesquisa PFOL.

A orientação dos alunos ocorria pela professora regente da disciplina que tinha duração de 4 horas semanais e também por um dos autores da presente pesquisa que era professora regente da turma de PFOL do programa de extensão (4 horas semanais em sala e 1 hora semanal para encontros de preparação). 
As três aulas ministradas pelas discentes foram preparadas a partir do objetivo definido na disciplina do Grupo de Pesquisa: abordar a transposição de diferentes gêneros textuais. Como haveria a festa junina do PFOL no final de junho, os alunos estrangeiros desenvolveram diferentes gêneros textuais que tinham relação com a festa: convite, cartaz, reportagem e receita de comidas típicas.

\section{Metodologia}

O presente estudo tem uma abordagem qualitativa interpretativista, tendo como base de análise os depoimentos dos alunos-professores participantes da pesquisa. Trata-se de um recorte inicial de uma tese de doutorado, ainda em andamento, pelo Programa de Pós Graduação em Estudos Linguísticos da Universidade Federal do Paraná. Os autores deste artigo são autora da pesquisa em desenvolvimento e professor orientador.

Os participantes, como já mencionado, são estudantes do curso de Licenciatura em Letras Inglês da UTFPR que, na época da geração dos dados, tinham 19 anos. Até a presente investigação, nunca haviam tido a experiência de docência em sala de aula. A realização do recorte feito do presente estudo consistiu em duas entrevistas realizadas do seguinte modo:

1) No início do semestre, os dois alunos de Letras Inglês foram entrevistados individualmente. Ambos receberam as perguntas com antecedência para que pudessem lê-las e já pensarem em suas respostas. A entrevista foi semiestruturada, gravada em áudio e depois transcrita integralmente para análise.

2) No final do semestre, depois de terminados os trabalhos aos quais nos dedicamos (tanto as aulas de PFOL, quanto o projeto piloto de pesquisa dos alunos), foi entregue a cada aluno uma cópia com a transcrição da entrevista realizada no início do semestre e com algumas observações da professora pesquisadora sobre algumas respostas que haviam sido dadas pelos participantes. Depois, houve uma segunda entrevista, cujo objetivo era confrontar as respostas dadas no início do semestre com o posicionamento atual dos alunos, depois de toda a experiência prática pedagógica que tiveram. A segunda entrevista também foi individual e também gravada em áudio e transcrita integralmente para análise. 
A análise se deu por meio da interpretação dos dados coletados na segunda entrevista, em confronto com a primeira.

\section{Análise dos dados}

Em ambas as entrevistas, os alunos relataram que a experiência com o PFOL foi sua primeira vivência como professor em sala de aula. A maioria das respostas indica que o trabalho com a prática foi fundamental para o entendimento dos conceitos teóricos vistos na disciplina do Grupo de Pesquisa PFOL, assim como conceitos teóricos emergiram da prática. Observemos a resposta do participante P1, quando questionado sobre o fato de a prática de sala de aula ter feito mais sentido no entendimento da teoria:

\section{EXCERTO 1:}

P1: Sim, sim. Fez mais sentido, mas é que, na prática, não é a mesma coisa que tá na teoria. É um recorte, um ponto de vista que tá lá na teoria.

Entrevistador: Tá, me explica isso então.

P1: Eh... bom, é o ponto de vista de quem escreveu, a gente pode recortar um monte de coisas desses pontos de vista. Mas a princípio, quando eu cheguei [nas aulas do PFOL], fez muito mais sentido o que eu tava lendo, muito mais. Lembro que teve uma que era da... acho que era Cinco Formas de Ver a Sala de Aula... cinco, quatro, três formas de ver a sala de aula... não lembro qual era o número. E quando eu vi assim, que falava muito do conflito e não é a palavra conflito em si, que ele trabalhava. É mais as opiniões diferentes, as cargas que cada um traz pra sala de aula, mas fez mais sentido, por mais que algumas coisas não estivessem muito equilibradas, tipo algumas palavras que ele usava assim, eram um pouco negativas. Mas deu pra fazer um recorte muito bom com a sala de aula, na prática.

Entrevistador: Você acha que o que você lia lá [na disciplina do Grupo de Pesquisa PFOL], de fato ajudou na sua prática? Refletiu?

P1: Sim, sim, da teoria sim. Eu não fiz prática específica em sala de aula. A gente observava... no grupo de pesquisa a gente observava mais sobre como, como é ensinar, não na prática exata. A gente pesquisa sobre português, sobre a gramática, discutia bastante sobre isso, mas a gente não tinha uma didática específica pra estar na sala 
de aula. Até porque nem todo mundo que estava nesse grupo conseguia estar na sala de aula [do PFOL]. (GRIFO NOSSO).

Lembremos que P1 estava no $2^{\circ}$ período do Curso de Licenciatura em Letras Inglês, portanto, muitos conceitos sobre ensino, sobre língua, sobre interculturalidade estão sendo vistos pela primeira vez. Assim, a oportunidade de poder experenciar o estudo da teoria aliado a situações reais de sala de aula já no início de sua formação é bastante significativo e nos mostra como ele pôde refletir sobre assuntos que estava lendo e estudando. É possível observar como ele foi capaz de relacionar um texto teórico que, segundo ele, falava sobre conflitos em sala de aula, com as situações vividas na sala de aula real. Tal experiência lhe fez refletir no modo como esses conflitos se configuram no espaço de aprendizagem.

Observemos a fala de P2 quando questionado sobre os conceitos teóricos do Exame Celpe-Bras ${ }^{2}$ estudados na disciplina Grupo de Pesquisa PFOL e a prática de sala de aula:

EXCERTO 2:

P2: Todos os artigos e todas as coisas que a gente leu e pesquisou, tudo linkava com as aulas do PFOL e o Celpe pra mim foi o centro de ideia pra preparar as aulas. Então tudo que a gente fez ali [nas aulas de PFOL] a gente tentou lembrar do Celpe e como é que ia trabalhar isso e aquilo, pelo menos as nossas atividades tavam bem conectadas.

Entrevistador: E você acha que teria sido diferente se você só tivesse estudado a teoria? "ah, esse aqui é o Celpe-Bras, essa é a teoria".

P2: Teria, se eu não tivesse participado das aulas ficaria mais difícil pra eu imaginar como é que ia ser, "como é que será que eles estudam? Como é que será que eles vão se sair escrevendo e fazendo isso, ou conversando"? Então como é que será? Como é que seria?

${ }^{2} \mathrm{O}$ exame Celpe-Bras é um exame de proficiência da língua portuguesa falada no Brasil. De acordo com suas diretrizes, ele tem base comunicativa e o candidato é avaliado por meio da realização de tarefas, tais como resposta a uma carta, preenchimento de um formulário, compreensão de um artigo de jornal ou de um programa de televisão. Não há questões de gramática ou de vocabulário, pois busca-se aferir a capacidade de uso da língua, uma vez que a competência linguística se integra à comunicativa. (BRASIL, 2015, p. 3). 
Ia ficar só imaginando, ia ser uma coisa idealizada minha, não o real, que eu vi.

Entrevistador: Quando você viu, qual que foi o impacto? Cê ver a coisa acontecendo?

P2: É bem legal, tipo você fala: "nossa, é de verdade. Nossa, é realmente assim". Eu até conseguia acrescentar mais às coisas que eu tava lendo pelas coisas que eu observava. "Nossa, não é só isso, é mais isso, isso, isso e aquilo". É, porque às vezes a gente fala: "ah, mas a teoria é assim, mas a prática não foi bem assim".

Percebemos pela fala de P2 que a experiência vivida na prática pôde trazer uma compreensão mais profunda da teoria, a ponto de ele resgatar os conceitos estudados na disciplina Grupo de Pesquisa PFOL para as atividades que ele preparava para os seus alunos reais. Além disso, ele entendeu que, muitas vezes, a teoria por si só pode ser limitada, já que a realidade nem sempre segue exatamente o que está escrito nos textos teóricos. Tal fato se deve à ideia de que uma sala de aula configura-se como um espaço plural, repleto de conflitos e as situações e resultados das interações são imprevisíveis. A formação docente precisa necessariamente trazer essa compreensão ao aluno-professor.

No excerto a seguir, P2 fala de como foi a experiência de ministrar as aulas e de como ele se sentiu:

EXCERTO 3:

P2: Tive a idealização de que todo mundo prestaria atenção, de que eu ia me dar bem, tipo escrever certo na lousa, que eu tinha vergonha. Teve essas pequenas frustrações, mas eu consegui... a gente conseguiu dar aula do jeito que a gente pensou, do jeito que a gente planejou, a gente conseguiu fazer tudo certinho... achava que eu não ia saber como planejar uma aula, daí fui pegando o jeito.

A fala do aluno nos mostra como, no momento do estudo teórico naturalmente idealizamos situações, idealizamos nosso aluno, o ambiente com o qual trabalharemos, mas quando estamos diante de um aluno real, em uma situação real, há muitas variáveis que podem interferir nessa idealização. A realidade nos traz situações impossíveis de prever com o estudo da teoria somente. 
No trecho da entrevista, a seguir, observamos como os conceitos vão sendo construídos a partir da experiência vivida por P2:

\section{EXCERTO 4:}

P2: Uma aula de língua não pode ser expositiva, isso é uma coisa que você sempre falou, chegar lá e falar, falar, falar, falar e o aluno anotar e tal. Aula de língua o aluno tem que ter... ele tem que praticar, ele tem que entender senão ele vai perder o foco, ele vai dormir,... é uma língua, ele tem que praticar, língua é uma coisa viva, não tem como só eu ficar falando.

F2: Uhum, e você acha que você meio que entendeu isso depois? Que você deu aula no PFOL?

F1: Aham. Eu comecei a refletir mais sobre isso, acho também que nem só uma aula de língua, toda aula não pode ser só expositiva. (GRIFO NOSSO).

A concepção de língua como algo vivo é um conceito que, com certeza, foi estudado por P2 em textos teóricos e em discussões em diferentes disciplinas do curso de Letras. Perceber como essa concepção se reflete em uma aula prática, uma aula real de línguas é um movimento que demanda não só leitura, mas muita reflexão em torno disso -- reflexão oriunda de dois movimentos: prática e estudo. A prática é oportunizada pelas aulas ministradas, a preparação dessas aulas, a preparação dos materiais didáticos, o modo como abordar a língua nesses materiais. Tudo isso vai auxiliando o aluno a construir a concepção de língua como algo vivo, que se constrói na interação, em práticas situadas sócio historicamente. Esse conceito discursivo de língua, discutido em textos teóricos de diferentes áreas da linguagem (PENNYCOOK, 2010; BLOMMAERT, 2005; BAKHTIN, 1986), não é, como parece, um conceito facilmente entendível por um professor iniciante; ele demanda reflexão, principalmente se buscarmos preparar nossas aulas de língua e materiais didáticos sob essa perspectiva.

A seguir, P2 nos relata como sentiu a importância de ver seu aluno e de escutá-lo. Percebemos em sua fala a formação de uma postura reflexiva, no sentido de sempre adequar seu posicionamento de acordo com a necessidade de seu aluno: 


\section{EXCERTO 5:}

P2: Eu adorei a aula que eu fiz, eu tenho orgulho da minha aula, só que... se o aluno não tá prestando atenção, então tem alguma coisa errada, eu vou ter que mudar o meu plano. Acho que nem sempre eu vou ser perfeito, não sou um deus só porque eu sou professor. Então você tem que ouvir o aluno, tem que ver... Acho que não é só você dar aula, você tem que prestar atenção em tudo ao seu redor, tem que analisar a produção do aluno, tem que analisar o aluno, tem que analisar o andamento da sua aula. São várias tarefas em uma só, eu acho.

No excerto a seguir, P1 é confrontada em relação a uma resposta que havia dado antes de sua experiência em sala, na $1^{\mathrm{a}}$ entrevista. Nessa ocasião ele havia definido o que, para ele, seria o papel de um professor de PFOL:

\section{EXCERTO 6:}

Entrevistadora: Eu te perguntei [na $1^{\mathrm{a}}$ entrevista] o que é ensinar português, o que é ser professor de português, daí você disse que é mais do que a língua, é ensinar cultura, ajudá-los a entender conceitos culturais, mais do que a gramática e mais do que a escrita em si. "Acho que você tá mais como um orientador", você disse, "um orientador da cultura, ajudando a conhecer a fala, a pronúncia", o que que cê acha?

P1: Eh... acho que... eu... não foi muito exatamente isso que eu fiz [durante as aulas ministradas no PFOL], mas eu ajudei nesses elementos culturais que ocorreram. Nessa época eu tava bem fissurado nesses elementos culturais.

Entrevistadora: O professor é realmente o cara que vai orientar mais a cultura? Que a cultura acaba sobressaindo a todas as outras coisas?

P1: Ela não, ela tá lá sim, ela é muito importante, mas não é só isso, cê tem que saber gramática pra estar lá. Tipo, foi uma das dificuldades que eu percebi assim, nossa, tem que estudar muita gramática. Eu tenho que ver que... não adianta estar lá sabendo da minha própria língua e nunca ter pensado nela desse jeito. Então a cultura sim, é muito importante porque eles tão aqui né, eles tão em imersão no nosso país, eles precisam saber como se portar em algumas situações que no país deles talvez não fosse tão necessário esse se portar. Mas levando em conta que é uma aula de língua, sim, a cultura é muito importante e, também, a gramática. 
Entrevistadora: Uhum, mas você acabou descobrindo isso durante as aulas [de PFOL]?

P1: Sim. Eu fui notando durante as aulas isso.

Entrevistadora: E você pode falar um pouco disso? Como que você...

P1: ...sim. Como que eu observei isso? Eh... eu observei porque eles [alunos estrangeiros] buscavam isso, buscavam bastante gramática. Não, não pensando nessa gramática normativa assim, específica, quadradinha assim, mas eles buscavam isso porque os artigos, principalmente para a leitura dos artigos... eu via bastante que eles buscavam muito isso porque não fazia sentido pra eles. E... e quando a gente estuda gramática a gente acha, faz muito sentido e você tenta explicar isso de uma forma... porque você sabe aquilo, você estudou aquilo pra saber. Eu me perdia bastante nisso assim, por que que...

Entrevistadora: ...na hora de explicar a estrutura?

P1: Por que que é... por que que é "do" e não é "da"? "Porque é uma palavra no feminino". "Tá, mas por que que ela é feminina?" Eu, eu, eu me vi sabe... sei, sei disso, mas como que eu vou explicar isso? Não estudei. Senti que isso me fez muita falta.

Percebemos como a percepção de P1 muda depois das aulas ministradas. Antes de dar aulas, tendo por base somente a leitura de textos teóricos das disciplinas do curso e a ideia de uma sala de aula idealizada, ele tinha uma percepção em relação aos conhecimentos necessários para dar aulas. Uma vez que se defrontou com uma sala real e alunos reais, sua percepção mudou. Ele se deu conta de que, mesmo sendo falante nativo do português, há determinados tipos de conhecimento que ele não possui e que lhes pareceram fundamentais para dar aula.

Nesse sentido, mesmo que não explicitado por ele nesse momento, ele também está percebendo outras questões, como, nesse caso, a do mito do falante nativo: não basta ser falante nativo de uma língua para poder ensiná-la. O nativo talvez tenha maior conhecimento da cultura do país, mas a relação que se estabelece entre língua e cultura (em sala de aula) não é necessariamente essa que é entendida como pertencente à determinada nacionalidade, ou seja, concebida na perspectiva da tríade herderiana (território-cultura-língua). 
Tal tríade entende que as línguas carregam a essência de uma determinada comunidade de falantes, ou seja, a língua é "capaz de expressar naturalmente somente os valores e pensamentos pertencentes a tal comunidade" (CANAGARAJAH, 2013, p. 20), vista e entendida como proprietária da língua. P1, no entanto, entende que não basta conhecer a cultura do país onde a língua é falada: é preciso outros conhecimentos (embora não chegue propriamente a questionar a relação entre língua, cultura e território). Ele se dá conta disso a partir da prática pedagógica.

No excerto a seguir, P1 fala sobre a relação gramática e cultura e de como ela se remodelou, depois da experiência vivida no PFOL:

EXCERTO 7:

Entrevistadora: Falamos sobre a relação gramática e cultura [na $1^{\mathrm{a}}$ entrevista]. Daí você disse: "acho que não tem um mais importante, acho que eles andam juntos, gramática e cultura, não tem como você falar que esse é mais importante. É importante para ele entender o contexto social da língua, mas não é mais importante que o outro". O que cê acha? Você acha que essa ideia persiste? Você gostaria de modificar, ampliar essa concepção? Depois dessa experiência que cê teve.

P1: Eh eles [gramática e cultura] são duas coisas separadas que estão juntas, penso assim. Agora os contextos são muito importantes, principalmente porque você vai usar, ou não, um tipo de gramática pra, pra cada contexto né. E é bom você saber cada um desses contextos, da gramática de cada um desses contextos. E... elas são... elas estão juntas, mas elas são coisas separadas assim, não sei. (GRIFO NOSSO).

Podemos ver refletidos os conceitos estudados em duas disciplinas cursadas por P1 naquele semestre: Grupo de Estudo PFOL e Estudos do Texto. Na primeira, foram muito discutidos os princípios norteadores do Exame Celpe-Bras (língua como discurso; gênero discursivo; função textual; formato do texto). Na segunda disciplina também foram trabalhados esses conceitos, mas de modo mais geral e não somente focalizando o exame CelpeBras. Assim, é possível perceber um movimento muito interessante no discurso de P1: ele vai construindo esses conceitos a partir das suas leituras e da experiência prática pela qual passou. 
Quando ele diz que "os contextos são muito importantes" e que "você vai usar um tipo de gramática para cada contexto”, ele está deixando claro que compreendeu que não existe uma única gramática aceitável (que seria a normativa) e que, de fato, utilizamos diferentes "gramáticas" (diferentes "línguas"), ou seja, diferentes modos de nos expressarmos em diferentes situações, dependendo de nossos objetivos e de nossos interlocutores. Como P1 escolheu abordar em suas aulas a transposição de diferentes gêneros textuais, ele teve a oportunidade de perceber como esses conceitos teóricos são abordados na prática de sala de aula desde o planejamento das aulas, passando pela elaboração de atividades, aplicação dessas atividades e, por fim, avaliação das produções dos alunos.

Também é curioso observar como ele admite que esses conceitos ainda estão sendo construídos por ele, ao dizer: “não sei...”. É como se houvesse dentro dele uma série de questões ainda para refletir que não se mostram muito claras, mas que, de alguma maneira, estão sinalizando para alguma direção. Retomamos a informações de que P1 ainda está no $2^{\circ}$ período e já está sendo confrontado com conceitos teóricos e situações reais de maneira bastante intensa. Tal movimento o faz refletir, como percebemos em suas falas. Os conceitos expostos por ele estão em um processo inicial de construção - tal posicionamento nos parece bastante positivo, pois o aluno está sendo questionado a todo instante e reflete sobre isso. Se retomarmos a definição de Gimenez (2005) de formação como um processo interventivo, concluímos que nosso papel, como formadores, é também o de levantar (gerar) dúvidas, questionamentos, de inquietar as certezas (FREIRE; FAUNDEZ; 1985; FREIRE, 1970/1987).

No excerto seguinte, P1 descreve como a experiência mudou sua visão sobre ser professor e ser aluno. Segundo ele, sua visão mudou depois de preparar e ministrar as aulas: EXCERTO 8:

P1: Eh... eu sou aluno, tô aprendendo inglês e me ver como professor, ensinando português fez com que eu visse que não é tão fácil ser um professor, mas também não é tão difícil ser um aluno. E não tem nada de impossível assim, não é muito difícil, mas você realmente tem que um trabalho em cima disso, pra ser professor você tem que ter aquele conhecimento e tem que pensar 
em várias coisas e se desenvolver pessoalmente. E você também tem que ser um bom aluno, como o português... o inglês que eu tô aprendendo assim.

Entrevistadora: Você acha que você mudou como aluno?

F2: Sim. Não que eu fosse antes um desleixado, mas eh... depois que você tá lá na frente você muda a forma de ver o professor. Eles não são mais só o meu professor, eles vão ser talvez os meus futuros colegas e o respeito é uma coisa muito importante né, de, de se trabalhar assim no grupo. (GRIFO NOSSO).

P1 redefine o que entende por docência, e gostaríamos de chamar a atenção para duas questões levantadas por ele: o trabalho docente demanda estudo e preparação, não se trata de uma atividade meramente intuitiva e exige o que ele chama de "desenvolvimento pessoal", ou seja, ele se dá conta de que, além do estudo, algo precisa mudar dentro daquele indivíduo professor. Ele precisará atentar para determinados pontos, refletir sobre eles e, se necessário, mudar de atitude, de postura e, muitas vezes, rever seus conceitos e crenças para atingir seu objetivo em sala de aula. Tais mudanças ocorrem por meio da prática e da reflexão docente: numa perspectiva social de aprendizagem, um professor se faz professor sendo, não há outro modo. Uma perspectiva socialmente situada pressupõe que os processos de aprendizagem sejam negociados por meio das práticas sociais das quais as pessoas participem, juntamente com todas os demais envolvidos em tais processos (JOHNSON, 2001).

O próximo excerto nos mostra de que modo P1 avalia toda a experiência pela qual passou ao longo do semestre:

EXCERTO 9:

P1: Foi muito rica essa experiência. Eu consegui enxergar coisas com outros olhos, não é só como tá sentado assim e esperar um monte de conhecimento entrar dentro de mim. Não, não foi assim. Tipo, como aluno. Mas... também, como futuro professor, teve coisas assim, que aconteceram que eu sei que eu vou levar pra sempre. A primeira aula eu sei que eu nunca vou esquecer na minha vida, mas não pelo lado negativo, porque quando eu saí de lá eu tava triste, que não foi o que eu esperava. Mas a vida também não 
é o que eu esperava e eu tenho que crescer com isso. (GRIFO NOSSO).

A parte destacada da fala de P1 nos mostra como a experiência lhe causou mudanças. Ele descreve a experiência que teve como muito diferente do que estar sentado esperando o conhecimento entrar nele. Tal relato nos indica que, de algum modo, a experiência prática lhe trouxe mais do que somente ler textos teóricos e estudá-los ou discuti-los, e mostra o quão imprevisível é a prática docente (SHON, 2000).

Por todos os excertos expostos ao longo de nossa análise foi possível observar o quanto os conceitos teóricos estudados pelos alunos em disciplinas do curso de Letras estavam presentes em seus discursos e foram repensados e construídos por meio da prática pedagógica na qual os alunos-professores se envolveram. Recordando que ambos vivenciaram toda essa dinâmica ainda no $2^{\circ}$ período do curso e ambos também eram bastante jovens, 19 anos, ou seja, estavam muito no início de sua formação e já tiveram a oportunidade de vivenciar o ambiente de sala de aula, de preparar materiais didáticos, de aplicá-los, de sentir as dificuldades, frustrações, de perceber que é preciso readequar o planejamento, que a vida real traz situações completamente imprevisíveis e que o professor em sala precisa lidar com tudo isso.

\section{Considerações Finais}

Os resultados preliminares deste estudo em andamento tendem a indicar que os conceitos teóricos são construídos por meio das experiências prático-pedagógicas vivenciadas pelos licenciados. Em outras palavras: a teoria faz muito mais sentido para os licenciados quando confrontada com a prática. Pelas análises das entrevistas, pudemos perceber como os alunos-professores vão construindo suas concepções: eles refletem, repensam, reavaliam e reconstroem seus conhecimentos sob a luz da experiência prática que tiveram.

Se admitirmos que o processo de formação deve ser um processo interventivo, isso significa que nossos alunos precisam ser levados a repensar suas opiniões, crenças, e escolhas. Tais mudanças acontecem se forem motivadas por situações relevantes para eles. A 
leitura de textos teóricos é muito importante e tem relevância na formação, mas não podemos nos limitar a ela somente e deixar a prática para o final do curso. Como pontuou P2, no EXCERTO 3, quando você pensa em alunos imaginários, a idealização é muito grande e você não é capaz de prever tudo o que pode acontecer, mesmo que sejam seus próprios medos e sentimentos naquele momento da aula: sensação de insegurança, receio por escrever no quadro, medo de ser confrontado. O aluno-professor só poderá entender essas questões quando estiver experimentando a prática.

Além disso, os dados indicam que a experiência prática não se encerra em si, mas tem efeitos claros na compreensão de aspectos teóricos estudados na formação discente. Assim, verificamos que não se trata de a teoria direcionar a prática ou vice e versa, mas de ambas formarem uma base de formação que se complementa.

\section{LA CONSTRUCCIÓN DE CONCEPTOS TEÓRICOS A TRAVÉS DE LA PRÁCTICA PEDAGÓGICA - FORMACIÓN DE PROFESORES DE LENGUAS}

RESUMEN: Este trabajo tiene como objetivo analizar, de acuerdo con la perspectiva de los alumnos profesores en formación inicial, de que manera el trabajo práctico desarrollado en la pasantía voluntaria durante clases de portugués para hablantes de otras lenguas (PFOL) ha colaborado con su formación docente en el curso de Letras Inglés de la Universidade Tecnológica Federal do Paraná (UTFPR). Para hacerlo, explicitaremos los conceptos de profesor reflexivo (SCHÖN, 1992; 2000) y articulación entre teoría y práctica en los cursos de letras (GIMENEZ, 2005; 2011; GIMENEZ e CRISTOVÃO, 2004). El trabajo tiene un abordaje cualitativo y los datos fueron originados a través de entrevistas semiestructuradas y transcriptas integralmente. Fueron entrevistados dos alumnos de los cursos de Letras, del $2^{\circ}$ período del curso. Ambos han participado como pasantes voluntarios en el programa de extensión universitaria PFOL en la UTFPR - Curitiba, cuyo objetivo es el atendimiento a extranjeros (clases de portugués). La formación inicial de profesores y el desarrollo de investigaciones en el área de enseñanza de PLA. Los resultados indican que la práctica propiciada por la participación de los discentes en el programa de extensión ha representado, para ellos, un avance significativo en su formación y que les ha auxiliado a relacionar conceptos teóricos abordados a lo largo del curso con la práctica pedagógica presentes en las clases de PFOL.

PALABRAS CLAVE: Enseñanza de PL2; Formación inicial de profesores; Teoría y práctica; Profesor reflexivo. 


\section{REFERÊNCIAS}

BALDIN, Fernanda D. C.; CORDEIRO, Elisa N. O Processo de Formação Inicial de Professores de Português para Falantes de Outras Línguas na UTFPR-CT: Integração entre Prática Pedagógica e Teoria. Em: Revista Linguas e Letras, v. 18, n. 39, 2017.

BRASIL. Celpe Bras. Manual do Examinando. Novembro de 2015. Disponível em < http://download.inep.gov.br/outras_acoes/celpe_bras/manual/2012/manual_examinando_celpebras.pdf $>$ Acesso em 01/02/2016.

BAKHTIN, Mikhail Mikhailovich. Speech Genres \& Other Late Essays. Austin: University of Texas Press, 1986.

BLOMMAERT, Jan. Discourse. Cambridge: Cambridge University Press, 2005.

CARAGARAJAH, Suresh. Translingual Practice: Global Englishes and Cosmopolitan Relations. New York: Routledge, 2013.

FIGUEIREDO, Eduardo Henrique. Second language acquisition in Brazil since the social turn. Em: Revista Brasileira Linguística Aplicada, v. 18 n. 1, Belo Horizonte Jan./Mar. 2018.

FREIRE, Paulo; FAUNDEZ, Antonio. Por uma Pedagogia da Pergunta. Rio e Janeiro: Paz e Terra, 1985.

FREIRE, Paulo. Pedagogia do Oprimido. São Paulo: Editora Paz e Terra, $17^{\mathrm{a}}$ ed., 1987.

GIMENEZ, Telma. Desafios contemporâneos na formação de professores de línguas: contribuições da linguística aplicada. Em: FREIRE, Maximina; ABRAHÃO, Maria Helena Vieira; BARCELOS, Ana Maria Ferreira (Orgs). Linguística aplicada e contemporaneidade. Campinas: Pontes, 2005.

. Tendências das pesquisas na área de formação de professores de línguas estrangeiras no contexto brasileiro. Em: BATTISTI, Elisa; GISE, A. Collischonn (Orgs). Lingua e Linguagem: perspectivas de investigação. Pelotas: Educat, 2011. p. 125-140.

GIMENEZ, Telma; CRISTÓVÃO, Vera Lucia Lopes. Derrubando paredes e construindo pontes: formação de professores de língua inglesa na atualidade. Em: Revista Brasileira de Linguística Aplicada, v. 4, n. 2, 2004.

HALU, Regina. Tese de Doutorado: Formação de formadoras de professoras de inglês em contexto de formação continuada (NAP-UFPR). Universidade Federal do Paraná, Curitiba, 2010.

JOHNSON, Karen. E.; FREEMAN, Donald. Teacher learning in second language teacher education: a socially-situated perspective. Revista Brasileira de Linguística Aplicada, 1(1), p. 53-69, 2001.

JOHNSON, Karen E. Second language teacher education: A sociocultural perspective. Routledge, 2009. 
. (2016). Language teacher education. Routledge handbook of English language teaching. New York: Routledge, 2016, p. 121-134.

MARTINEZ, Juliana Zeggio. Dissertação de Mestrado: Uma leitura sobre concepções de lingua e educação profissional de professores de lingua inglesa. Universidade Federal do Paraná, Curitiba: 2007.

PENNYCOOK, Alistair. Language as a Local Practice. Abingdon: Routledge, 2010.

SCHÖN, Donald. Formar professores como profissionais reflexivos. Em: NOVOA, A. Os professores e a sua formação. Dom Quixote, 1992.

. Educando o profissional reflexivo. Porto Alegre: Artmed, 2000.

Wallace, Michael. Training foreign language teachers: a reflective approach. Melbourne: Carnbridge University Press, 1991.

ZAMBONI, Alessandra da S. Q. Dissertação de Mestrado: A formação do professor de língua inglesa: um estudo interpretativo das ementas na formação inicial. Universidade Federal do Paraná. Curitiba, 2013.

Recebido em: 29/05/2019.

Aprovado em: 16/07/2019. 